\title{
Home-based pulmonary rehabilitation in patients with chronic obstructive pulmonary disease: a randomized clinical trial
}

This article was published in the following Dove Press journal:

International Journal of COPD

4 November 2013

Number of times this article has been viewed

\author{
Fernanda Dultra Dias' \\ Luciana Maria Malosá \\ Sampaio' \\ Graziela Alves da Silva' \\ Évelim LF Dantas Gomes' \\ Eloisa Sanches Pereira \\ do Nascimento' \\ Vera Lucia Santos Alves ${ }^{2}$ \\ Roberto Stirbulov ${ }^{2}$ \\ Dirceu Costa' \\ 'Post Graduate Program in \\ Rehabilitation Sciences, Nove de Julho \\ University - UNINOVE, São Paulo, \\ Brazil; ${ }^{2}$ Pneumology Clinic at Santa \\ Casa de Misericórdia de São Paulo \\ (AME), São Paulo, Brazil
}

Correspondence: Dirceu Costa Post Graduate Program in Rehabilitation Sciences, Nove de Julho University, UNINOVE, LARESP, I09 Barra Funda, São Paulo - SP 0I I56-050, Brazil

Tel +55 II3665 987।

Email dcosta@uninove.br
Introduction: Pulmonary rehabilitation (PR) is a multidisciplinary program of care for patients with chronic obstructive pulmonary disease (COPD) with the goal of improving the functional capacity and quality of life, as well as maintaining the clinical stability of COPD sufferers. However, not all patients are available for such a program despite discomfort with their condition. The aim of this study was to evaluate the effects of a home-based PR (HBPR) program on functional ability, quality of life, and respiratory muscle strength and endurance.

Patients and methods: Patients with COPD according to the Global Initiative of Chronic Obstructive Lung Disease were randomized (double-blind) into two groups. One group performed a protocol at home with aerobic and muscle strength exercises and was called the intervention group; the other group received only instructions to perform breathing and stretching exercises, characterizing it as the control group (CG). We assessed the following variables at baseline and 2 months: exercise tolerance (incremental shuttle walk test and upper limb test), respiratory muscle (strength and endurance test), and health-related quality of life (Airways Questionnaire 20).

Results: There were no significant changes after the intervention in either of the two groups in exercise tolerance and quality of life. However, the intervention group had improved respiratory endurance compared with the CG, while the CG presented a decrease in the load sustained by the respiratory muscles after the HBPR.

Conclusion: A program of HBPR with biweekly supervision (although not enough to provide significant improvements in physical capacity or quality of life) played an important role in maintaining the stability of the clinical features of patients with COPD; the patients had no worsening of symptoms during the intervention period according to the daily log.

Keywords: home-based pulmonary rehabilitation, COPD, shuttle walk test

\section{Introduction}

Chronic obstructive pulmonary disease (COPD) is a preventable and treatable respiratory illness characterized by the presence of chronic airflow obstruction; however, due to its chronicity, it is progressive and not fully reversible. ${ }^{1}$ In addition to affecting the lungs, COPD also produces significant systemic consequences ${ }^{2}$ requiring constant care and treatment, such as resistive exercises for respiratory muscles and general physical exercises, which may be part of a pulmonary rehabilitation (PR) program. ${ }^{3-6}$

The PR consists of a multi-disciplinary program of care for patients with COPD, which currently includes nutrition guidelines, guidelines on medications, as well as physical training methods and respiratory muscle. The purpose of these methods is to maintain clinical stability and improve the functional capacity and quality of life of these patients, especially those who, even with optimal medical therapy, remain 
symptomatic with a reduction of their physical and social functioning. ${ }^{7-9}$ PR goals include symptom reduction, reduction of functional loss caused by lung disease, and optimization of physical and social activities, which are reflected in improved quality of life, and helping the patient maintain and maximize functional independence. ${ }^{10-12}$

For these goals to be achieved, a patient with COPD should adhere to a PR program with monitoring and attendance at least three times per week for several months. However, not all patients can consistently perform PR, either for professional reasons or for lack of economic motivation to present themselves at rehabilitation centers as often as necessary, leading to low treatment adherence. The result of this is that the patient loses the opportunity to obtain the benefits provided by PR. ${ }^{13}$

Thus, the need for alternative solutions becomes clear, such as home-based PR (HBPR), which, besides being a viable alternative, can also assist in maintaining a patient's physical condition and preventing exacerbations of the disease itself. ${ }^{14}$ This alternative treatment can be monitored every 2 weeks or monthly and can be accompanied by periodic therapist visits, via patient attendance to a clinic (whenever possible) or via telephone and other media..$^{9,14,15}$

The quality of life and exercise capacity in patients with COPD have been shown to improve after an HBPR program, especially in those with severe obstruction. ${ }^{2}$ At a follow-up of up to 18 months, the maintenance of clinical symptoms and no changes in the functional capacity in patients with moderate and mild obstruction have also been shown. ${ }^{16-18}$ However, there remains a lack of studies on this type of PR, especially regarding the rigor and accuracy of data records (because HBPR is not an attendance-based activity) and a lack of information regarding patient adherence to treatment. No records were found in the literature for the type of exercises that these patients should perform at home. Guidelines for how to execute HBPR are also lacking. These aspects justify an attempt to further elucidate these and other issues to further inform HBPR. Furthermore, there is a growing tendency for patients to encounter difficulties when searching for specialized PR centers and the incidence of COPD has increased annually. ${ }^{1,19,20}$ Thus, the aim of this study was to evaluate the effects of a PR program (HBPR) on functional capacity, quality of life, and respiratory muscle strength and endurance.

\section{Materials and methods Protocol}

This study was a randomized, double blind clinical trial and was registered with the protocol number NCT01554072. It was duly approved by the UNINOVE Institutional Ethics Committee (protocol number 384767/2011), as well as by National Council for Scientific and Technological Development with the protocol numbers 508715/2010-5, 479256/2011-0 and 473183/2012-9. A sample of patients with COPD who underwent outpatient care were screened at a specialty-based public outpatient service.

We included patients of both sexes aged 40 years or more and diagnosed with COPD according to the Global initiative for chronic Obstructive Lung Disease (GOLD). ${ }^{2}$ They had to be clinically stable with no signs of disease exacerbation in the last 30 days and could not be participating in any program involving concurrent physical activity. All included subjects agreed to participate in this study and, after being informed about its objectives, signed a statement of informed consent.

The exclusion criteria for this study were as follows: patients with severe comorbidities, such as previous heart disease, orthopedic diseases in the upper limbs and lower limbs, motor sequelae of neurological or visual disorders that could interfere with physical exercise, uncontrolled hypertension, associated lung diseases, or those who did not agree to participate in the study.

We calculated the power of the sample at $80 \%$, assuming an alpha error of 0.05 , based on a study that determined the clinically significant difference for the incremental shuttle walk test (ISWT) ${ }^{20}$ at 78.7 meters with a standard deviation calculated using a pilot study of 98.59 meters. This calculation resulted in a sample size of at least 20 patients.

\section{Experimental procedure}

All patients underwent spirometric evaluation for classification of the severity of obstruction according to the recommendations of the American Thoracic Society, ${ }^{21}$ and all tests were conducted in an air-conditioned environment using a Koko spirometer PFT ${ }^{\circledR}$ (n Spire Health, Inc., Longmont, CO, USA), which was previously calibrated. The reference values used were in accordance with those in Pereira et al. ${ }^{22}$

After screening and spirometric evaluation, all patients underwent (on the same day) the following tests: respiratory muscle strength (RMS), muscular endurance respiratory assessment training load upper limb, and ISWT, with rests of 5-10 minutes between each test.

\section{RMS}

The RMS was measured using a manometer made WIKAMV300 (Brasil Indústria Comércio, Iperó, Brazil) in $\mathrm{cmH}_{2} \mathrm{O}$ and equipped with an air escape valve to relieve the pressures of the buccal wall. We obtained measurements for maximum 
inspiratory and expiratory pressures, according to the procedure used by Black and Hyatt, ${ }^{23}$ with patients seated and wearing a nose clip. Each maneuver was sustained for at least 1 second and was repeated at least five times and at most eight times. The highest value was computed as long as it did not exceed $10 \%$ of the lower value. ${ }^{24}$

\section{Endurance of respiratory muscles}

The ERM was obtained using a linear load device called POWER ${ }^{\circledR}$ breathe (POWERbreathe a division of HaB International Ltd, Southam, UK). To this end, the protocol consisted of two steps, namely the incremental test and the constant load test. In the incremental test, the patient was instructed to breathe into the oral apparatus, which was initially graduated with a load of $10 \mathrm{cmH}_{2} \mathrm{O}$ for 2 minutes with 1 minute of rest. At each new 2-minute step, the load was increased by $10 \mathrm{cmH}_{2} \mathrm{O}$. The inability of the patient to achieve the proposed load in the respective step or the failure to achieve a duration of 2 minutes halted the test. After the end of the incremental loading protocol, the patient had a 10-minute rest. After this period, the constant load protocol was then started. In this test, the patient was instructed to breathe for as long as he/she could (a maximum of 30 minutes) with a load of $80 \%$ of the maximum reached in the incremental test. The device was connected to a manometer to control the pressures generated by the patient, serving to provide feedback to the patient about the pressures achieved with each breath. Prior to and after the end of each step of the protocol, data regarding oxygen saturation $\left(\mathrm{SpO}_{2}\right)$, heart rate $(\mathrm{HR})$, Borg dyspnea, and blood pressure were obtained..$^{25,26}$

\section{Upper limbs incremental test}

To evaluate the upper limbs incremental test (ULIT) training load, the patients were instructed to perform the movement once in diagonal primitive using the dominant upper limb for 2 minutes with equal rest in the standing position, starting with a weight of $0.5 \mathrm{~kg}$ and progressing by a $0.5 \mathrm{~kg}$ increase with each new series of movements. The maximum load was the heaviest weight moved without using offsets from other muscles. The maximum load recorded was that prior to any motion compensation. Additional oxygen was supplied to the patient if the $\mathrm{SpO}_{2}$ was less than $80 \%{ }^{27}$

\section{ISWT}

Two ISWT tests were conducted by a trained assessor in a 10-meter long hallway, which was marked using two cones placed at $0.5 \mathrm{~m}$ from the end of the path and with the support of a device creating an audible beep, dictating the tempo of the test, as standardized by Singh et al. ${ }^{28}$ Oxygen supplementation could be given if the patient had an arterial desaturation below $80 \%$. Between each test, a 15-minute rest was given to the patient so that his/her vital signs returned to baseline levels. However, if needed, more time was given to the patient to return to pre-test values. ${ }^{28}$ The estimated distance was calculated using the formula presented by Singh et al. ${ }^{20}$

\section{Airways Questionnaire 20}

The Airways Questionnaire 20 (AQ-20) is specific for COPD patients and consists of 20 questions related to the impact of the disease on daily life. Each question should be answered with "yes" or "no," and 1 point is awarded for each yes. The final score ranges from 0 to 20 points; the higher the score, the worse the quality of life reported. This questionnaire was administered before and after the HBPR. $^{29}$

\section{Randomization}

After the evaluations, the patients were randomized (using sealed envelopes) into two groups, one being the intervention group (IG) and the other being the control group (CG). Group membership information was restricted to the coordinator of the experiment, and both the patients and the assessors (physical therapists specially trained to evaluate selected patients) were blinded to group membership. The guidelines were made by a third person who was aware of the groups but did not perform any other tasks in the experiment.

\section{Intervention}

\section{The IG}

After randomization, the patients in the IG received a booklet of exercises containing an explanation of their illness and the impact on their quality of life of practicing these exercises. A global stretching routine, respiratory re-education exercises, and aerobic exercises for the upper limbs (with individual load determined in $50 \%$ of the load obtained after the evaluation) were to be conducted at home. ${ }^{27}$

Furthermore, after performing the ISWT at baseline, each patient was instructed to walk for 40 minutes $^{30,31}$ on flat ground at least three times per week ${ }^{30,31}$ at $85 \%$ of peak oxygen consumption, derived from ISWT performance. ${ }^{20}$ In an attempt to instruct the patients in the standardization of the method, each patient underwent a simulation on the treadmill at their prescribed walking speed on the first day of evaluation. This time, they were also asked 
to measure their symptoms using the Borg scale, trying to remain between items 4 and 6 to better control their walks at home. ${ }^{32}$

The patients were individually instructed on each exercise, performing each with the assessor/tutor, thus minimizing doubt about their execution and possible errors in domestic practice. All patients were asked to record the data on a monitoring diary or each completed day of exercise. This diary was given away with the booklet and was intended to be given back to the instructor monthly, at which point they would receive a new diary. This method was intended to record the time spent on the physical exercise routine, possible complications, exacerbation of symptoms (for early drug treatment if necessary), as well as serving to reinforce the commitment of adherence to the PR.

Bi-weekly visits to the laboratory were scheduled in which each patient would demonstrate his/her exercise routine, including the intensity of their walk at home. At this time, we would assess whether the HR achieved at that speed was within the range of training (85\% ISWT) and, if it was not, new guidelines were provided to the patient. On this occasion, we would also perform load adjustments, postural corrections, and adjustments in the execution of physical exercise.

At the end of the 2 months of planned HBPR, ${ }^{30,31}$ the patients underwent reassessment, and all tests were reapplied.

\section{The CG}

Also after randomization, patients in the $\mathrm{CG}$ received a brochure containing exercises, along with a brief explanation of their illness and the importance of physical exercise for improving their quality of life, as well as a routine of global stretching exercises and respiratory re-education exercises. These patients were instructed to perform a sequence of exercises three times per week ${ }^{30,31}$ for two consecutive months.

To monitor the home activities and reinforce their commitment to the HBPR, all patients were instructed to write down in a tracking diary ${ }^{30,31}$ the days on which they should practice their exercise routine and the time spent in the practice of this physical exercise routine, as well as possible complications and exacerbation of symptoms so that early drug treatment could be administered if necessary. Biweekly visits to the laboratory were scheduled in which patients were encouraged to continue their exercise routine and were asked to demonstrate their exercise routine, to receive instructions on corrections and enhancements, and to record possible complications.
Similar to the IG, at the end of the 2-month follow-up, ${ }^{30,31}$ all patients in the $\mathrm{CG}$ also underwent reassessment.

\section{Adherence}

Adherence was defined as the consent of the patients in undergoing the HBPR treatment.

\section{Treatment and data analysis}

After the verification of the data distribution, the KolmogorovSmirnov test was used to analyze the within-group variables, and Student's $t$-test and the Wilcoxon test were used for parametric and nonparametric variables, respectively. In the intragroup analysis, we used the paired $t$-test. For the intergroup analysis, we used the unpaired $t$-test for parametric variables and the Mann-Whitney test for the nonparametric variables. The results were considered statistically significant at $P \leq 0.05$.

\section{Results}

Patients with COPD were screened in specialized services; among those who met the criteria for inclusion in the study, only 27 agreed to participate, of which four did not complete the protocol because two were suspended for heart problems, one experienced an exacerbated condition during the protocol, and another subject was hospitalized for tuberculosis, leaving a final sample of 23 patients, of which 14 were males.

According to the data in Table 1 and the characterization of the sample with the anthropometric data, there were no significant differences between the groups. The anthropometric variables (as in the spirometric evaluations) as well as the physical ability and quality of life among the groups also did not show any significant difference, denoting homogeneity

Table I Mean and standard deviations of demographic variables, the lung function measurements, and functional capacity

\begin{tabular}{|c|c|c|c|}
\hline Variables & $\begin{array}{l}\text { IG } \\
N=12 \\
\text { (9 females) }\end{array}$ & $\begin{array}{l}\text { CG } \\
N=I I \\
(5 \text { males })\end{array}$ & $P$-value \\
\hline Age (years) & $66.5 \pm 5.8$ & $64.0 \pm 5.8$ & 0.523 \\
\hline Weight (kg) & $66.4 \pm 18.1$ & $61.8 \pm 19.1$ & 0.500 \\
\hline Height (m) & $1.63 \pm 0.1$ & $\mathrm{I} .6 \mathrm{I} \pm 0 . \mathrm{I}$ & 0.606 \\
\hline BMI $\left(\mathrm{kg} / \mathrm{m}^{2}\right)$ & $25.3 \pm 5.6$ & $24.3 \pm 7.3$ & 0.642 \\
\hline $\mathrm{FEV}_{1}(\mathrm{~L})$ & $1.58 \pm 0.83$ & $1.63 \pm 0.8$ & 0.913 \\
\hline $\mathrm{FEV}_{1}(\%$ predicted $)$ & $55.14 \pm 24.8$ & $60.0 \pm 20.1$ & 0.709 \\
\hline $\mathrm{FEV}_{1} / \mathrm{FVC}(\mathrm{L})$ & $0.51 \pm 0.15$ & $0.51 \pm 0.13$ & 0.990 \\
\hline $\mathrm{FEV}_{\mathrm{I}} / \mathrm{FVC}$ (\% predicted) & $66.8 \pm 21.2$ & $65.16 \pm 17.5$ & 0.880 \\
\hline ISWT (m) & $297.4 \pm 98.5$ & $275.1 \pm 105$ & 0.6446 \\
\hline $\begin{array}{l}\text { AQ-20 median (minimum } \\
\text { and maximum value) }\end{array}$ & $12(3-18)$ & $10(4-20)$ & 0.7914 \\
\hline
\end{tabular}

Abbreviations: AQ-20, Airways Questionnaire 20; BMI, body mass index; CG, control group; FEV , forced expiratory volume in I second; FVC, forced vital capacity; IG, intervention group; ISWT, incremental shuttle walk test. 
among the two groups. There were no cases of the exacerbation of clinical manifestations in patients with COPD in the IG during HBPR, while two CG patients needed antibiotics for treating symptom exacerbation, according to the reports made by the patients in their diaries.

The values relating to $\mathrm{SpO}_{2}, \mathrm{HR}$, arterial blood pressure, as well as Borg for the lower limbs, upper limbs, or dyspnea (as needed for each test) were recorded. None of these variables showed significant differences between the groups, either pre- or post-intervention.

Table 2 shows the results of the ISWT, ULIT, and AQ-20. The ISWT distance was not different from that of the HBPR, nor did it differ between both groups. No significant differences were found between the groups after the HBPR on the ULIT. No significant differences were found between the groups after the HBPR in the scores of the AQ-20.

As can be seen in Table 3, the RMS (measured via maximum inspiratory and expiratory pressures) were different after the HBPR treatment between the IG and CG groups. There was no difference between these groups in the preintervention analysis.

The ERM showed significant between-group differences. When the constant load test results were compared, there was a significant difference between load time sustained in the IG and CG groups. No significant between-group differences were detected for the ULIT.

In addition, there was a significant amount of low adherence. Of the 58 patients included in this study, only 27 agreed to participate in the HBPR program.

\section{Discussion}

There were no significant intergroup or intragroup differences in the distance walked on the ISWT after the HBPR. In the IG patients, an increase in respiratory endurance time was noted, indicating that in addition to the aerobic exercises, they also trained peripheral muscle strength. This did not occur with the CG patients, who showed reduced respiratory endurance strength. Despite these results, patients in both groups reported no improvement in quality of life on the questionnaires. It should be noted that Singh et $\mathrm{al}^{20}$ found that patients who reported feeling "better" showed an average increase of $78.7 \mathrm{~m}$ on the ISWT 7 weeks after applying PR in the office or at home, while those who reported feeling the same showed a mean improvement of $18 \mathrm{~m}$ after the intervention. It may be necessary to achieve more marked improvement in physical performance for patients with COPD to notice any quality of life improvements.

Using a similar methodology, Resqueti et $\mathrm{al}^{9}$ found no differences in increased respiratory muscle strength in their patients. However, an improvement in the distance of the 3-minute walk test (148 $\mathrm{m}$ to $167 \mathrm{~m}$ ) was observed in the group that received the intervention. This group also experienced an improved quality of life. ISWT was the method of assessment in this study. It should be noted that, unlike our patients, the patients of the Resqueti et $\mathrm{al}^{9}$ and Singh et $\mathrm{al}^{20}$ studies received conventional $\mathrm{PR}$ and therefore were already more familiar with the exercise routine.

Similar to our results, Maltais et $\mathrm{al}^{30}$ found a slight improvement in the distance walked in the 6-minute walk test after HBPR (approximately 8-10 m) with reported improvement in COPD symptoms.

The non-significant change in the distance traveled by these patients after HBPR is possibly due to, among other factors, a lack of stimulation and verbal encouragement during walks at home (where the sheer scale of the Borg scale, being a subjective scale, may have underestimated heart rate training). This occurred with our patients even though they received counseling on verifying HR pulse

Table 2 Mean and standard deviations of the values obtained on the ISWT, ULIT, and AQ-20

\begin{tabular}{|c|c|c|c|c|}
\hline \multirow[t]{2}{*}{ Variables } & \multicolumn{2}{|l|}{ IG $(n=13)$} & \multicolumn{2}{|l|}{ CG $(n=10)$} \\
\hline & Pre-PR & Post-PR & Pre-PR & Post-PR \\
\hline \multicolumn{5}{|l|}{ ISWT } \\
\hline ISWT (m) & $297.4 \pm 98.5$ & $318.2 \pm 100.8$ & $275.1 \pm 105$ & $272.2 \pm 125.6$ \\
\hline \% ISWT (predicted) & $64.2 \pm 23.6$ & $63.8 \pm 20.5$ & $56.3 \pm 27.1$ & $56.6 \pm 26.5$ \\
\hline HR maximum & $113.2 \pm 17.9$ & $112.5 \pm 15.3$ & $104.8 \pm 15.0$ & $99.5 \pm 14.9$ \\
\hline$\% \mathrm{HR}$ maximum & $74.1 \pm 11.5$ & $73.4 \pm 10.0$ & $67.6 \pm 8.95$ & $64.3 \pm 9.7$ \\
\hline \multicolumn{5}{|l|}{ ULIT } \\
\hline Load (kg) & $\mathrm{I} . \mathrm{I} \pm 0.5$ & $1.3 \pm 0.8$ & $0.8 \pm 0.5$ & $0.9 \pm 0.5$ \\
\hline $\mathrm{SpO}_{2}$ & $95 \pm 1$ & $95 \pm 2$ & $93 \pm 3$ & $94 \pm 4$ \\
\hline \multicolumn{5}{|l|}{ AQ-20 } \\
\hline Score (minimum and maximum value) & $12(3-18)$ & $15(0-18)$ & $10(4-20)$ & II (3-20) \\
\hline
\end{tabular}

Abbreviations: \% HR maximum, percentage of the predicted maximum HR; \% ISWT, percentage of the predicted value on the ISWT; AQ-20, Airways Questionnaire 20; CG, control group; IG, intervention group; ISWT, incremental shuttle walk test; HR, heart rate; PR, pulmonary rehabilitation; ULIT, upper limbs incremental test. 
Table 3 Mean and standard deviations of the values of respiratory muscle strength and their percentage of predicted values and load values obtained on the respiratory muscle endurance test incremental

\begin{tabular}{|c|c|c|c|c|}
\hline \multirow[t]{2}{*}{ Variables } & \multicolumn{2}{|l|}{ IG $(n=13)$} & \multicolumn{2}{|l|}{ CG $(n=10)$} \\
\hline & Pre-PR & Post-PR & Pre-PR & Post-PR \\
\hline MIP $\left(\mathrm{cmH}_{2} \mathrm{O}\right)$ & $62.1 \pm 12.2$ & $76.9 \pm 21.5$ & $71.0 \pm 15.9$ & $73.1 \pm 14.3$ \\
\hline$\%$ predicted $\left(\mathrm{cmH}_{2} \mathrm{O}\right)$ & $65.1 \pm 11.0$ & $74.2 \pm 19.3$ & $71.1 \pm 16.7$ & $70.2 \pm 13.9$ \\
\hline $\operatorname{MEP}\left(\mathrm{cmH}_{2} \mathrm{O}\right)$ & $86.0 \pm 41.9$ & $89.5 \pm 40.8$ & $72.5 \pm 22.7$ & $75.5 \pm 20.3$ \\
\hline$\%$ predicted $\left(\mathrm{cmH}_{2} \mathrm{O}\right)$ & $77.9 \pm 38.8$ & $82.7 \pm 38.3$ & $51.6 \pm 21.7$ & $53.7 \pm 22.9$ \\
\hline \multicolumn{5}{|l|}{ Incremental load } \\
\hline Maximum load $\left(\mathrm{cmH}_{2} \mathrm{O}\right)$ & $32.5 \pm 16.6$ & $37.5 \pm 16.6$ & $26.7 \pm 19.0$ & $20.0 \pm 16.0$ \\
\hline \multicolumn{5}{|l|}{ Constant load } \\
\hline $80 \%$ of maximum load $\left(\mathrm{cmH}_{2} \mathrm{O}\right)$ & $21.2 \pm 12.4$ & $26.2 \pm 13.0$ & $21.2 \pm 12.4^{*}$ & $16.2 \pm 9.1$ \\
\hline Sustained time (seconds) & $365.6 \pm 219.2$ & $314.0 \pm 96.0^{\dagger}$ & $208.7 \pm 103.9$ & $202.2 \pm 81.9$ \\
\hline
\end{tabular}

Notes: *Intra-group difference; †difference between groups.

Abbreviations: CG, control group; IG, intervention group; MEP, maximum expiratory pressure (positive); MIP, maximum inspiratory pressure (negative); PR, pulmonary rehabilitation.

and speed in the household routine during biweekly visits. Additionally, the follow-up time was insufficient to observe gains in physical capacity, as reported by Maltais et $\mathrm{al}^{30}$ and Kortianou et al. ${ }^{33}$

According to a systematic review on this topic, Thomas et $\mathrm{al}^{34}$ warn of a small number of studies that emphasized respiratory training and report changes in the profile of respiratory muscle strength after HBPR.

Studies on home training with the use of a respiratory muscle training device detected an improvement of dyspnea.

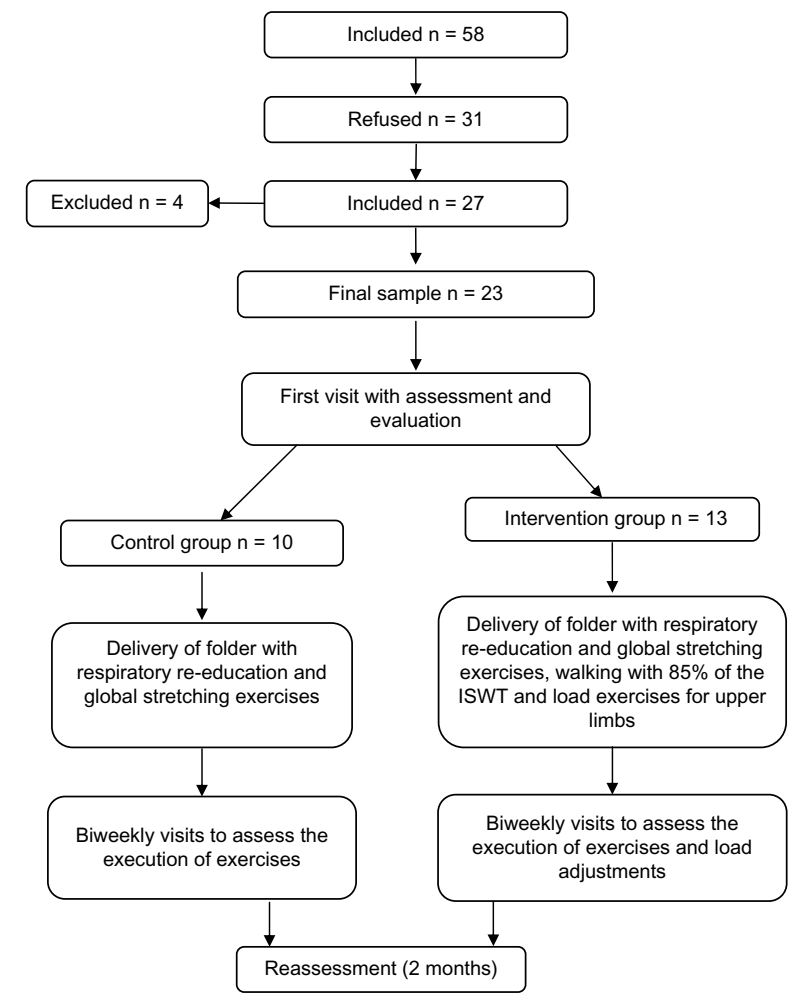

Figure I Consort diagram.

Abbreviation: ISWT, incremental shuttle walk test.
However, similar to our findings, they did not detect changes in respiratory muscle strength. In our HBPR methodology, we did not employ the inspiratory muscle training itself (using load) but instead orientation for respiratory exercises for both groups.

In a systematic review, Lötters et $\mathrm{al}^{35}$ observed improvement in physical performance in RMS after aerobic training and RMS together only in patients with respiratory muscle weakness. Smith et $\mathrm{al}^{36}$ concluded that respiratory muscle training in patients with COPD does not provide clinical improvement. The training of respiratory muscle strength, although widely studied, remains controversial, as this cannot be changed even if applying specific loads.

Regardless of the results mentioned in the literature on this topic, we must consider the influence of various factors related to individual aspects, which lead to significant changes in the results, evidenced here by the high standard deviation in the average of many variables, such as the distance traveled. A lack of awareness in these patients regarding the prognosis of the disease may be a factor in adherence. We observed a low adherence to treatment, despite cost-free HBPR prescription and guidelines. Additionally, a total of 31 patients who also fulfilled the inclusion criteria did not participate, citing various reasons, such as lack of time and other priorities.

Low adherence to treatment remains unaddressed and underreported in the literature on the subject (as seen in Figure 1). According to Beckerman et al, ${ }^{26}$ some studies have failed to find long-term benefits for quality of life in patients with COPD, the reason being the barriers related to the psychological factors of the patients themselves. Social factors, high incidence of exacerbations, and severity of the disease are other factors that influence poor adherence to an exercise program. ${ }^{26}$ 


\section{Limitations}

In addition to low treatment adherence, another significant limitation of this study is the lack of a better device to assist in maintaining the requirement of aerobic exercise at home, such as a pedometer or a frequency meter; the correction of walking speed at each biweekly visit appears to have not been sufficient to ensure the correct execution of the walk (despite prior prescription and modification of the protocol as time progressed).

\section{Conclusion}

Although HBPR did not provide significant improvement in pulmonary function variables and physical capacity (as commonly observed in patients with COPD who undergo conventional PR programs), a program of HBPR with biweekly supervision can play an important role in maintaining the stability of the clinical features of patients with COPD.

\section{Acknowledgment}

Funding was provided by the Laboratory of Functional Respiratory Assessment (LARESP) - UNINOVE.

\section{Disclosure}

The authors report no conflicts of interest in this work.

\section{References}

1. Sociedade Brasileira de Pneumologia e Tisiologia. II Consenso Brasileiro de Doença Pulmonar Obstrutiva Crônica.(DPOC). [Brazilian Thoracic Association. III Brazilian Thoracic Association Guidelines on COPD]. J Bras Pneumol. 2004;30:1-52. Portuguese.

2. Global Initiative for Chronic Obstructive Lung Disease [homepage on the Internet]. Global strategy for the diagnosis, management, and prevention of chronic obstructive pulmonary disease, 2013. Available from: http:// www.goldcopd.org/uploads/users/files/GOLD_Report_2013_Feb20.pdf. Accessed May 02, 2012.

3. Zaina F, Negrini S. EJPRM systematic continuous update on Cochrane reviews in rehabilitation: news from July to December 2011. Eur J Phys Rehabil Med. 2011;47(4):601-605.

4. Neder JA. Strategies for the skeletal muscle reconditioning in COPD. In: Terra Filho M, Fernandes ALG, Stirbulov R, editors. Pneumologia: atualização e reciclagem. São Paulo: Vivali; 2001:1-13.

5. Dourado VZ, Godoy I. Recondicionamento muscular na DPOC: principais intervenções e novas tendências. [Muscle reconditioning in COPD: main interventions and new tendencies]. Rev Bras Med Esporte. 2004; 10(4):331-334.

6. Ware LB. Interstitial lung disease, pulmonary vascular disease, pulmonary infections, and cardiopulmonary exercise testing and pulmonary rehabilitation. Am Thorac Soc. 2009;6:487-493.

7. Rodrigues SL, Viegas CAA, Lima T. Efetividade da reabilitação pulmonar como tratamento coadjuvante da doença pulmonar obstrutiva crônica. [The effectiveness of the pulmonary rehabilitation program as an ancillary treatment for chronic obstructive pulmonary disease]. $J$ Pneumologia. 2002;28(2):65-70. Portuguese.

8. Bourbeau, J. Making pulmonary rehabilitation a success in COPD. Swiss Med Wkly. 2010;140(w13067).
9. Resqueti RV, Gorostiza A, Gáldiz JB, López de Santa María E, Casan Clarà $\mathrm{P}$, Güell Rous R. Benefits of a home-based pulmonary rehabilitation program for patients with severe chronic obstructive pulmonary disease. Arch Bronconeumol. 2007;43(11):599-604. Spanish.

10. Nici L, Donner CF, Wouters EF, et al; ATS/ERS Pulmonary Rehabilitation Writing Committee. American Thoracic Society/European Respiratory Society statement on pulmonary rehabilitation. Am J Respir Crit Care Med. 2006;173:1390-1413.

11. Nici L, Zuwallack R. Scope, background and definition of pulmonary rehabilitation. Eur J Phys Rehabil Med. 2011;47(3):465-474.

12. Ike D, Jamami M, Marino DM, Ruas G, Pessoa BV, Di Lorenzo VAP. Efeitos do exercício resistido de membros superiores na força muscular periférica e na capacidade funcional do paciente com DPOC. [Effects of the resistance exercise in upper limb on peripheral muscular strength and functionality of COPD patient]. Fisioter Mov. 2010;23(3):429-437. Portuguese.

13. Ries AL. Position paper of the American Association of Cardiovascular and Pulmonary Rehabilitation: scientific basis of pulmonary rehabilitation. J Cardiopulm Rehabil. 1990;10(11):418-441.

14. Liu WT, Wang CH, Lin HC, et al. Efficacy of a cell phone-based exercise program for COPD. Eur Respir J. 2008;32(3):651-659.

15. Wijkstra PJ, Van Altena R, Kraan J, Otten V, Postma DS, Koëter GH. Quality of life in patients with chronic obstructive pulmonary disease improves after rehabilitation at home. Eur Respir J. 1994;7(2):269-273.

16. Wijkstra PJ, Ten Vergert EM, van Altena R, Otten V, Kraan J, Koëter GH. Long term benefits of rehabilitation at home on quality of life and exercise tolerance in patients with chronic obstructive pulmonary disease. Thorax. 1995;50(8):824-828.

17. Vieira DRS, Maltais F, Borbeau, J. Home-based pulmonary rehabilitation in chronic obstructive pulmonary disease patients. Curr Opin Pulm Med. 2010;16(2):134-143.

18. Chapman KR, Mannino DM, Soriano JB, et al. Epidemiology and costs of chronic obstructive pulmonary disease. Eur Respir J. 2006;27(1): 188-207.

19. Yaksic MS, Toro M, Cukier A, Stelmach R. Perfil de uma população brasileira com doença pulmonar obstrutiva crônica grave. [Profile of a Brazilian population with severe chronic obstructive pulmonary disease]. J Pneumol. 2003;29(2):64-68. Portuguese.

20. Singh SJ, Jones PW, Evans R, Morgan MD. Minimum clinically important improvement for the incremental shuttle walking test. Thorax. 2008;63(9):775-777.

21. Standardization of Spirometry, 1994 Update. American Thoracic Society. Am J Respir Crit Care Med. 1995;152(3):1107-1136.

22. Pereira CAC, Barreto SP, Simöes JG, Pereira FWL, Gerstler JG, Nakatani J. Valores de referência para a espirometria em uma amostra da populaçäo brasileira adulta. [Reference values for spirometry in Brazilian adults]. J Pneumol. 1992;18(1):10-22. Portuguese.

23. Black LF, Hyatt RE. Maximal respiratory pressures: normal values and relationship to age and sex. Am Rev Respir Dis. 1969;99(5):696-702.

24. Costa D, Gonçalves H, de Lima L, Ike D, Cancelliero K, Montebelo M. Novos valores de referência para pressões respiratórias máximas na população brasileira. [New reference values for maximal respiratory pressures in the Brazilian population.] J Bras Pneumol. 2010;36(3):306-312. Portuguese.

25. Magadle R, McConnell AK, Beckerman M, Weiner P. Inspiratory muscle training in pulmonary rehabilitation program in COPD patients. Respir Med. 2007;101(7):1500-1505.

26. Beckerman M, Magadle R, Weiner M, Weiner P. The effects of 1 year of specific inspiratory muscle training in patients with COPD. Chest. 2005;128(5):3177-3182.

27. Roceto LS, Takara LS, Machado L, Zambon L, Saad IAB. Eficácia da reabilitação pulmonar uma vez na semana em portadores de doença pulmonar obstrutiv. [Effectiveness of pulmonary rehabilitation once a week for patients with obstructive pulmonary disease]. Rev Bras Fisioter. 2007;11(6):475-480. Portuguese.

28. Singh SJ, Morgan MD, Scott S, Walters D, Hardman AE. Development of a shuttle walking test of disability in patients with chronic airways obstruction. Thorax. 1992;47(12):1019-1024. 
29. Camelier A, Rosa F, Jones P, Jardim JR. Validação do questionário de vias aéreas 20 ("Airways questionnaire 20" - AQ20) em pacientes portadores de doença pulmonar obstrutiva crônica (DPOC) no Brasil. [Validation of the Airways questionnaire 20 - AQ20 in patients]. J Pneumol. 2003;29(1):28-35. Portuguese.

30. Maltais F, Bourbeau J, Shapiro S, et al; Chronic Obstructive Pulmonary Disease Axis of Respiratory Health Network, Fonds de recherche en santé du Québec. Effects of home-based pulmonary rehabilitation in patients with chronic obstructive pulmonary disease: a randomized trial. Ann Intern Med. 2008;149(12):869-878.

31. Effing T, Zielhuis G, Kerstjens H, van der Valk P, van der Palen J. Community based physiotherapeutic exercise in COPD self-management: a randomized controlled trial. Respir Med. 2011;105(3):418-426.

32. Horowitz MB, Mahler DA. Dyspnea ratings for prescription of crossmodal exercise in patients with COPD. Chest. 1998;113(1):60-64.
33. Kortianou EA, Nasis IG, Spetsioti ST, Daskalakis AM, Vogiatzis I. Effectiveness of interval exercise training in patients with COPD. Cardiopulm Phys Ther J. 2010;21(3):12-19.

34. Thomas MJ, Simpson J, Riley R, Grant E. The impact of home-based physiotherapy interventions on breathlessness during activities of daily living in severe COPD: a systematic review. Physiotherapy. 2010; 96(2):108-119.

35. Lötters F, van Tol B, Kwakkel G, Gosselink R. Effects of controlled inspiratory muscle training in patients with COPD: a meta-analysis. Eur Respir J. 2002;20(3):570-576.

36. Smith K, Cook D, Guyatt GH, Madhavan J, Oxman AD. Respiratory muscle training in chronic airflow limitation: a meta-analysis. Am Rev Respir Dis. 1992;145(3):533-539.

\section{Publish your work in this journal}

The International Journal of COPD is an international, peer-reviewed journal of therapeutics and pharmacology focusing on concise rapid reporting of clinical studies and reviews in COPD. Special focus is given to the pathophysiological processes underlying the disease, intervention programs, patient focused education, and self management protocols.

\section{Dovepress}

This journal is indexed on PubMed Central, MedLine and CAS. The manuscript management system is completely online and includes a very quick and fair peer-review system, which is all easy to use. Visit $\mathrm{http} / / / \mathrm{www}$.dovepress.com/testimonials.php to read real quotes from published authors.

Submit your manuscript here: http://www.dovepress.com/international-journal-of-copd-journal 